\title{
ANKYLOSING SPONDYLITIS AND PROLONGED ACTH THERAPY
}

\author{
BY \\ H. F. WEST and G. R. NEWNS \\ Sheffield Centre for the Investigation and Treatment of Rheumatic Diseases
}

(RECEIVED FOR PUBLICATION APRIL 5, 1954)

The maintenance of prolonged adrenal stimulation by the administration of ACTH is still an experimental procedure and as yet little detailed information on the subject has been published. The six cases described below are presented as much for the light they throw on this subject as for the information they provide about the benefits that patients suffering from ankylosing spondylitis may derive from this form of therapy. The six patients received ACTH continuously for from $1 \frac{1}{2}$ to 2 years. During the latter half of the treatment period adrenocortical activity was studied by assays of urinary 17-ketosteroids (17-KS) and urinary 17ketogenic steroids (17-KGS), using the methods described by Norymberski and others (1953).

The majority of patients with ankylosing spondylitis can be treated satisfactorily with aspirin, phenylbutazone, and deep $x$-ray therapy. Their spines can be kept straight, they can be kept at work most of the time, and in many the movements of the thorax can be maintained. Severe cases, unfortunately, derive only temporary relief from deep $x$-ray therapy, and when their hip joints are affected they suffer considerable permanent disability. It was patients considered to be of this type who were selected for prolonged ACTH therapy.

In addition to the observations recorded below, monthly estimations of haemoglobin, packed cell volume, white blood count, plasma proteins, fibrinogen, and cholesterol were made. These have not been recorded in the diagrams because it was thought that the minor variations observed were of insufficient interest.

\section{Case Reports}

Case 1, a man aged 30, was, in our opinion, beyond any but palliative treatment when first seen. The entire spine and thorax were rigid, the hip joints were largely destroyed, and all the peripheral joints were swollen and tender. The fingers were hyperextended and powerless and the feet and toes plantar flexed. The bones of all the joints were grossly osteoporosed and he had multiple small renal calculi. He had lain helpless for the preceding 9 months. In addition to the ACTH and cortisone acetate therapy he had much active physiotherapy and manipulation. Seven months after starting treatment he was walking unaided, had a strong grip, and was able to attend to all his own needs. The chart tells its own story. The record of symptoms represents a clinical impression of the degree of pain, stiffness, and disability attributable to the active disease process; 100 per cent. denotes a state of complete helplessness, with all its attendant pain, due to active disease, and 50 per cent. a state in which the patient can only get about with great difficulty, with the help of analgesics every 3-4 hours, again because of active disease. The main problem in this case was that of hypertension; the diastolic blood pressure rose to dangerous heights when he was away from hospital for 2 months on a dose of H.P. Acthar Gel that proved to be excessive (10 "units" twice daily). The rise in the urinary output of $17-\mathrm{KGS}$ to above $100 \mathrm{mg}$., equivalent to a daily adrenal secretion of over $200 \mathrm{mg}$. hydrocortisone, suggests that the preparation used contained an adrenal growth factor (West, 1954). The fact that considerable adrenal stimulation continued when only 5 "units" were injected each day tends to confirm this. The most surprising happening in this case was that the bone density in the patient's hands returned almost to normal in less than 9 months (Figs $1 a$ and $b$, $2 a$ and $b$, overleaf). We have seen nothing like it in rheumatoid arthritis treated with ACTH or cortisone acetate. This suggests yet another point of difference between these two diseases. Of importance are the acute relapses with fever that occurred on the two days in February, 1954, when injections were missed (Fig. 3, overleaf). Sudden major reductions in dosage, after prolonged therapy, are dangerous in severe rheumatic diseases.

This patient is very grateful for the benefits that he has gained from treatment and we would advocate similar treatment for others like him but for the hypertension. Whether this treatment will prove valuable to him in the long run depends upon whether the hypertension can be overcome without the occurrence of a severe relapse. In the last few weeks he had been transferred to hydrocortisone $60 \mathrm{mg}$. daily by mouth. So far there has been no serious relapse and his blood pressure has begun to fall. 


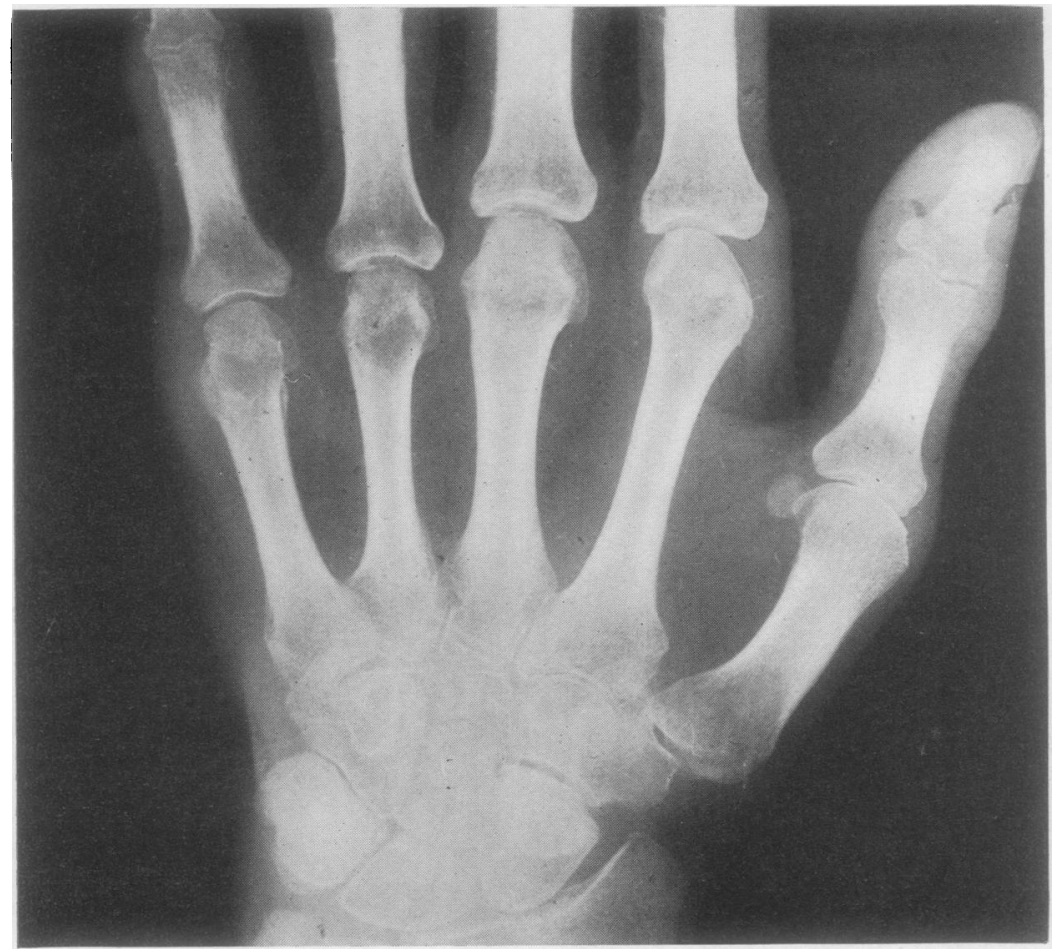




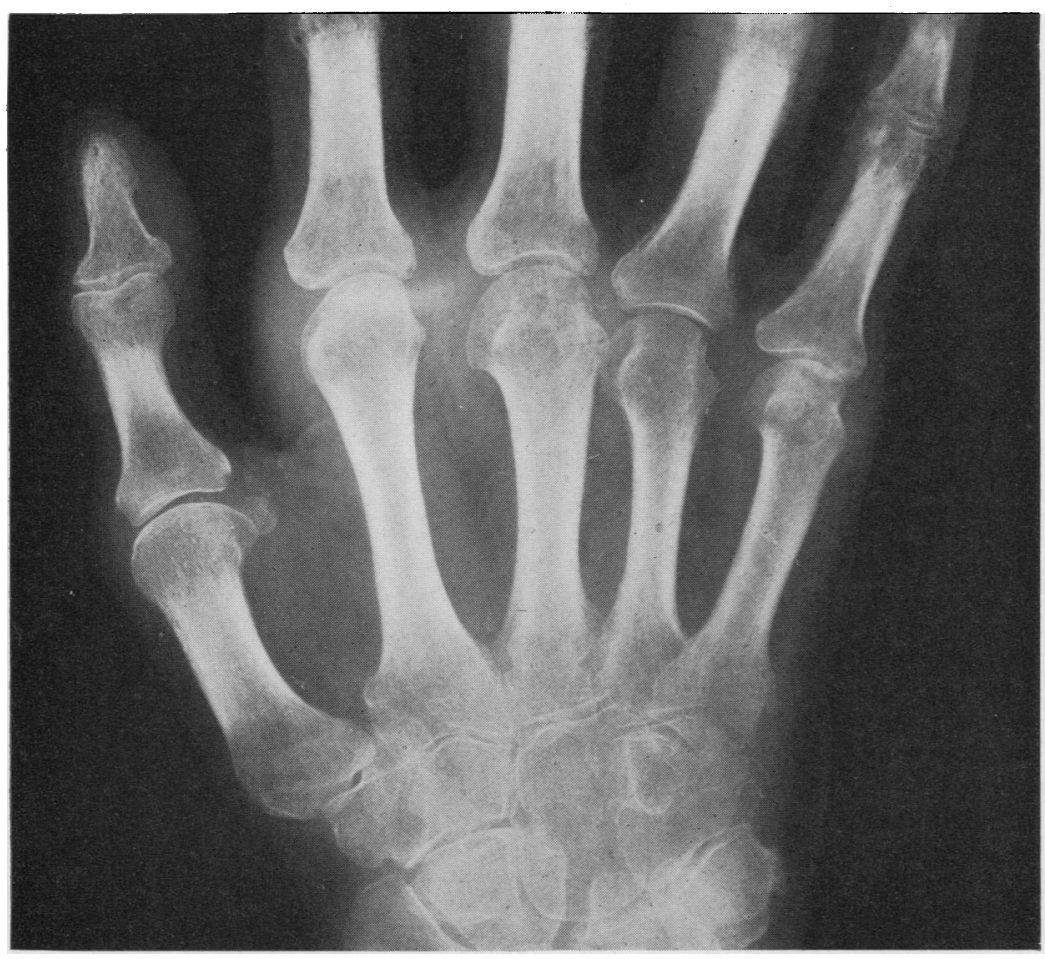

Fig. 1(b).-Case 1 in July, 1952, right hand.

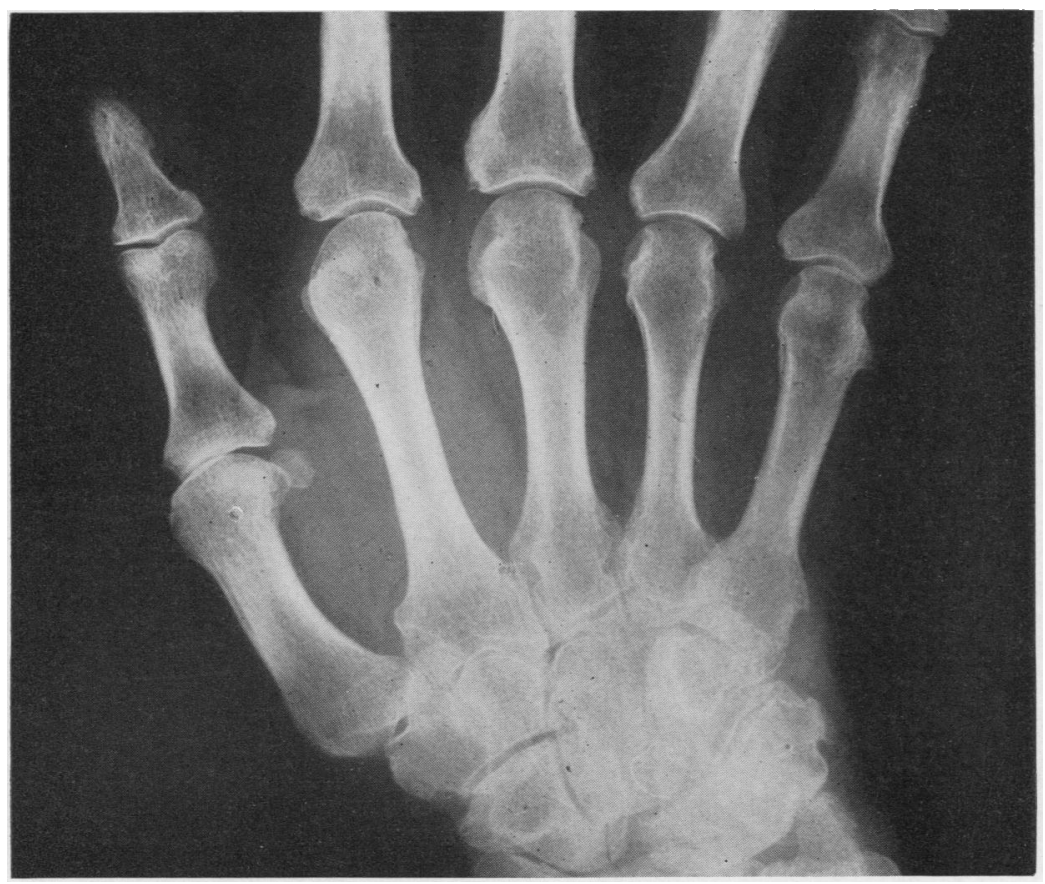

Fig. 2(b).-Case 1 in October, 1953, right hand 

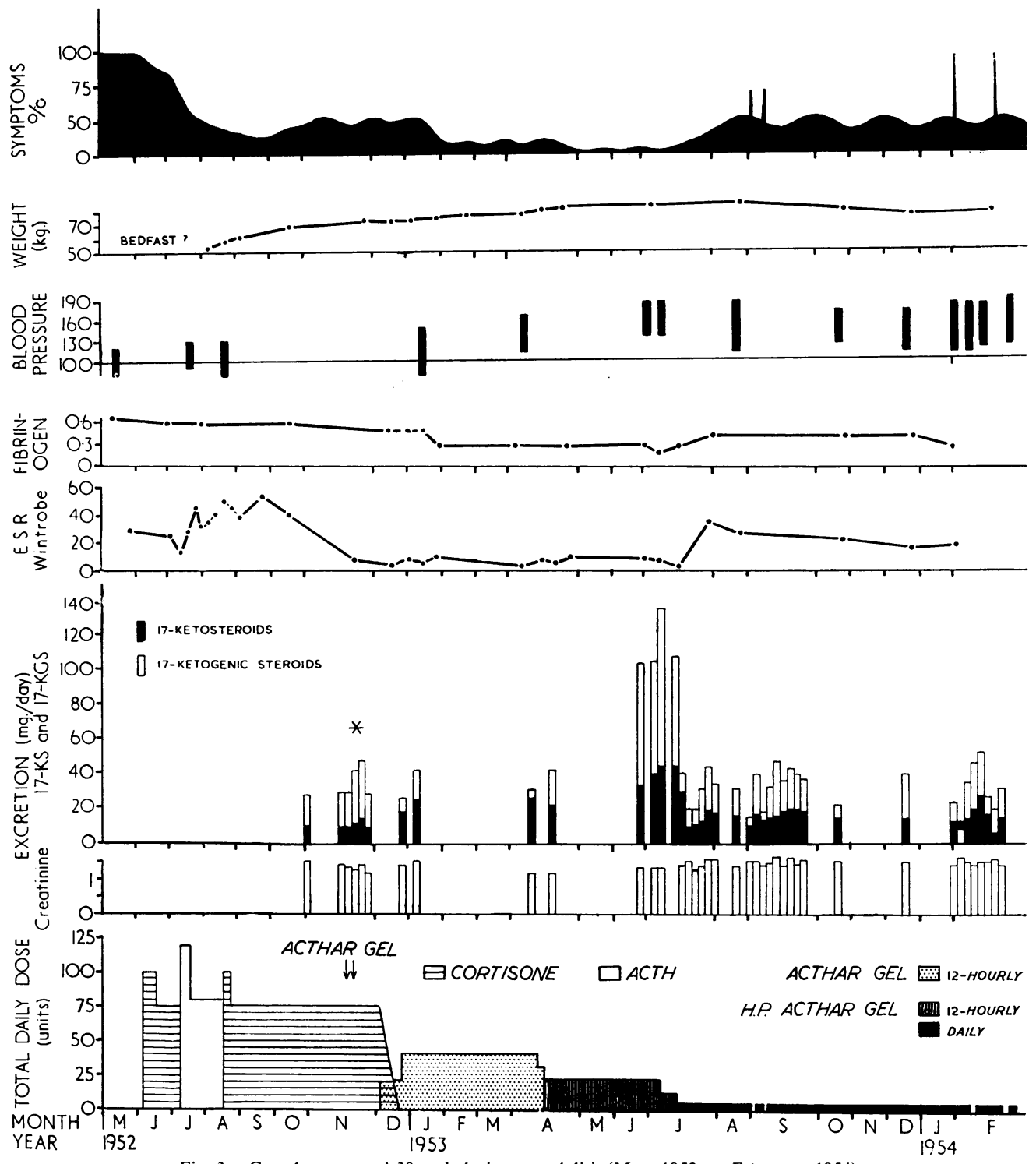

Fig. 3.-Case 1, man aged 30, ankylosing spondylitis (May, 1952, to February, 1954).

* A series of assays were made on November 25-29, 1952, and injections of Acthar Gel were given in addition to Cortisone on November 26 and 27,1952 .

Case 2, a man aged 36, was treated in the hope of saving his second hip joint, the first having already suffered considerable damage. His spine was rigid and, as in Case 1, he had already had as much deep $x$-ray therapy as it was safe to give. After a severe febrile relapse in February, 1952, he was rehabilitated, taught a new job at a technical college, and found a suitable post. The frequent changes in ACTH dosage reflect a running battle to keep the adrenal stimulation down in order to prevent hypertension. On a number of occasions he raised the dose himself so that he might not lose any time from work (!) Of particular note is the reversal of the $17-\mathrm{KS} / 17-\mathrm{KGS}$ ratio during the latter months of his treatment. In this unit several hundre $\$$ assays of the 17-KS and 17-KGS excretions have been made for patients receiving $\mathrm{ACTH}$; it has been foun $\Phi$ that, at least in the early months of treatment, the excreo tion of 17-KGS always exceeds the excretion of 17-K\$ when the excretion of $17-\mathrm{KS}$ has risen to above $25 \mathrm{mgs}$ Exceptions sometimes occur on a day following a markef reduction in ACTH dosage. In this patient the excretio 5 of $17-\mathrm{KGS}$ fell in the course of a year by 100 per cent yet the excretion of $17-\mathrm{KS}$ remained unaltered. It likely that the increased output of $17-\mathrm{KS}$ seen during 

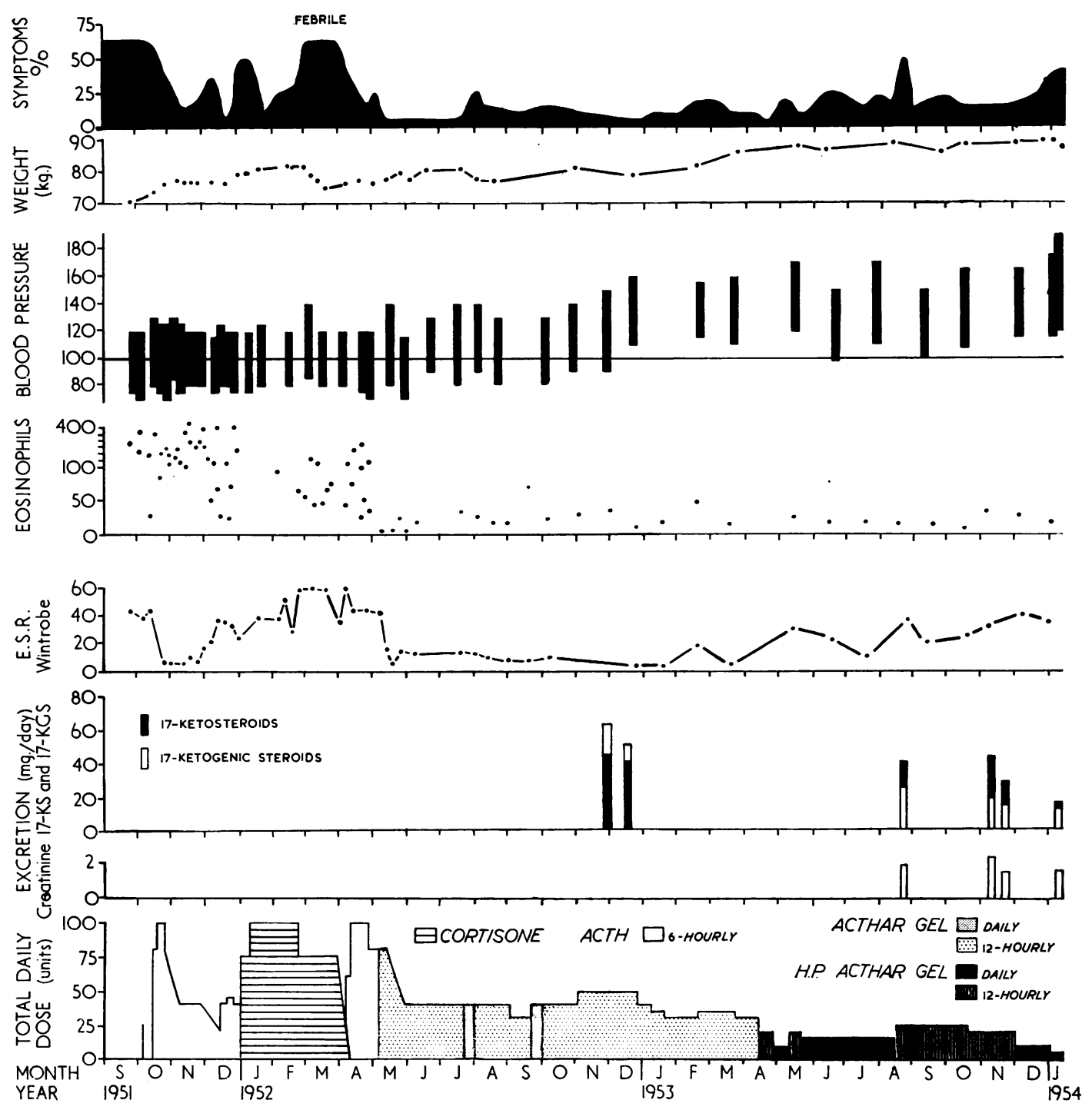

Fig. 4.-Case 2, man aged 36, ankylosing spondylitis (September, 1951, to January, 1954)

adrenal stimulation represents largely corticosteroid precursors and not degradation products as often supposed. The results of assays in August and November, 1953, suggest that either the adrenal had become less efficient in its synthesis of hydrocortisone or that the 17-KS increase represented, in part, precursors of some other corticosteroid. Now, in our experience of other patients receiving ACTH or cortisone acetate, an output of 20-25 mg. per day of 17-KGS, though long continued, is not accompanied by hypertension. Hence it is likely that some corticosteroid other than hydrocortisone was being secreted by this patient's adrenal. This other non-17-KGS corticosteroid might well have been cortico- sterone or even aldosterone (Simpson and others, 1954). The latter would, of course, be secreted in very small amounts and would not be expected to have a measurable effect upon the 17-KS excretion. If an adrenal steroid other than hydrocortisone were responsible for the sustained hypertension, one would expect the blood pressure to fall following the suppression of adrenocortical activity by withdrawal of ACTH therapy and the administration of hydrocortisone. Since the completion of Fig. 4 the ACTH injections have been stopped and $60 \mathrm{mg}$. hydrocortisone given daily. The blood pressure has fallen significantly (from $190 / 120$ to $145 / 105$ ) in the course of 8 weeks, although the output of 17-KGS 

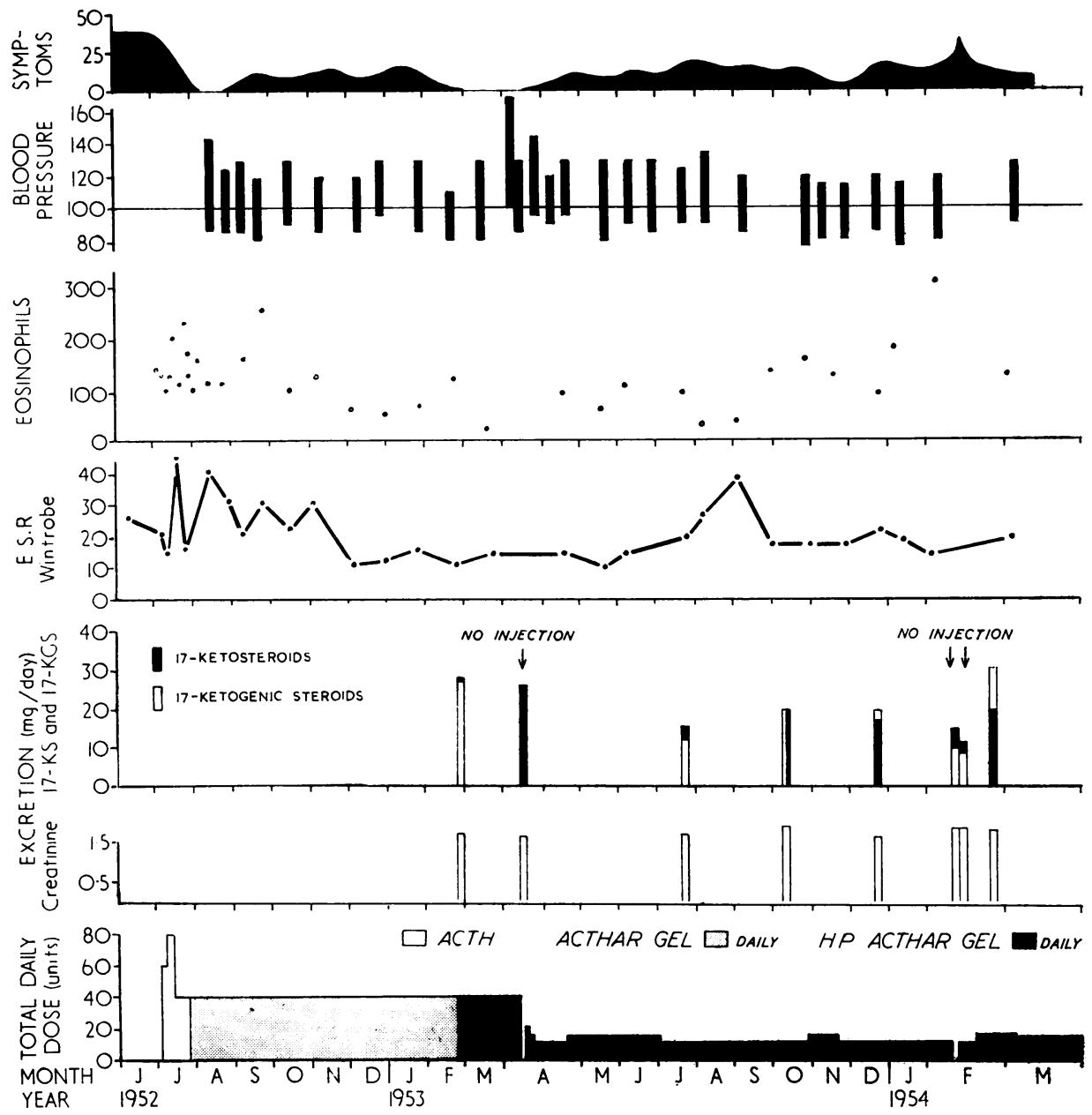

Fig. 5.-Case 3, woman aged 32, ankylosing spondylitis (June, 1952, to March, 1954)

has risen to $30 \mathrm{mg}$. (50 per cent. of administered hydrocortisone is normally recovered as $17-\mathrm{KGS})$. Whatever the interpretation of the altered $17-\mathrm{KS} / 17-\mathrm{KGS}$ ratio in this case, this phenomenon must be considered as a complication of prolonged ACTH therapy.

This patient would say that he has derived benefit from this course of treatment, but we must conclude, since we cannot see into the future, that we may have done more harm than good. The right hip for which treatment was begun has remained symptom-free but both knees have become swollen and effused.

Case 3, a woman aged 32, was treated because of persistent groin pain in the hope that destructive changes in the hip joints might be prevented. She had had four courses of deep $x$-ray therapy. The lumbar and dorsal spine was rigid and the neck movements restricted by about 50 per cent. Fig. 5 shows what happens when
Acthar Gel is replaced by H.P. Acthar Gel. When given in a single daily dose, as this patient had had throughout, these preparations are supposed to be equalły potent. The H.P. unit contains one-third as muef ACTH (assayed by the Sayers technique, Sayers an others, 1948) as the ordinary gel. When seen soon aftep changing to H.P. Gel the patient was "full of the wild joys", but by the end of the 6th week she felt blown us extremely irritable, and tense, and could not sleep. Tत्छ continue the dose in order to collect a $24-\mathrm{hr}$ specimen for assay was not justified, but, from the result of the assay made on the 24-hr specimen when no injection had been given, one can deduce that on the previous day the output must have been very high.

The patient maintains that for the 20 months she ha remained very much better and able to do more tha before treatment. Clinically and radiologically toes disease does not appear to have advanced. 

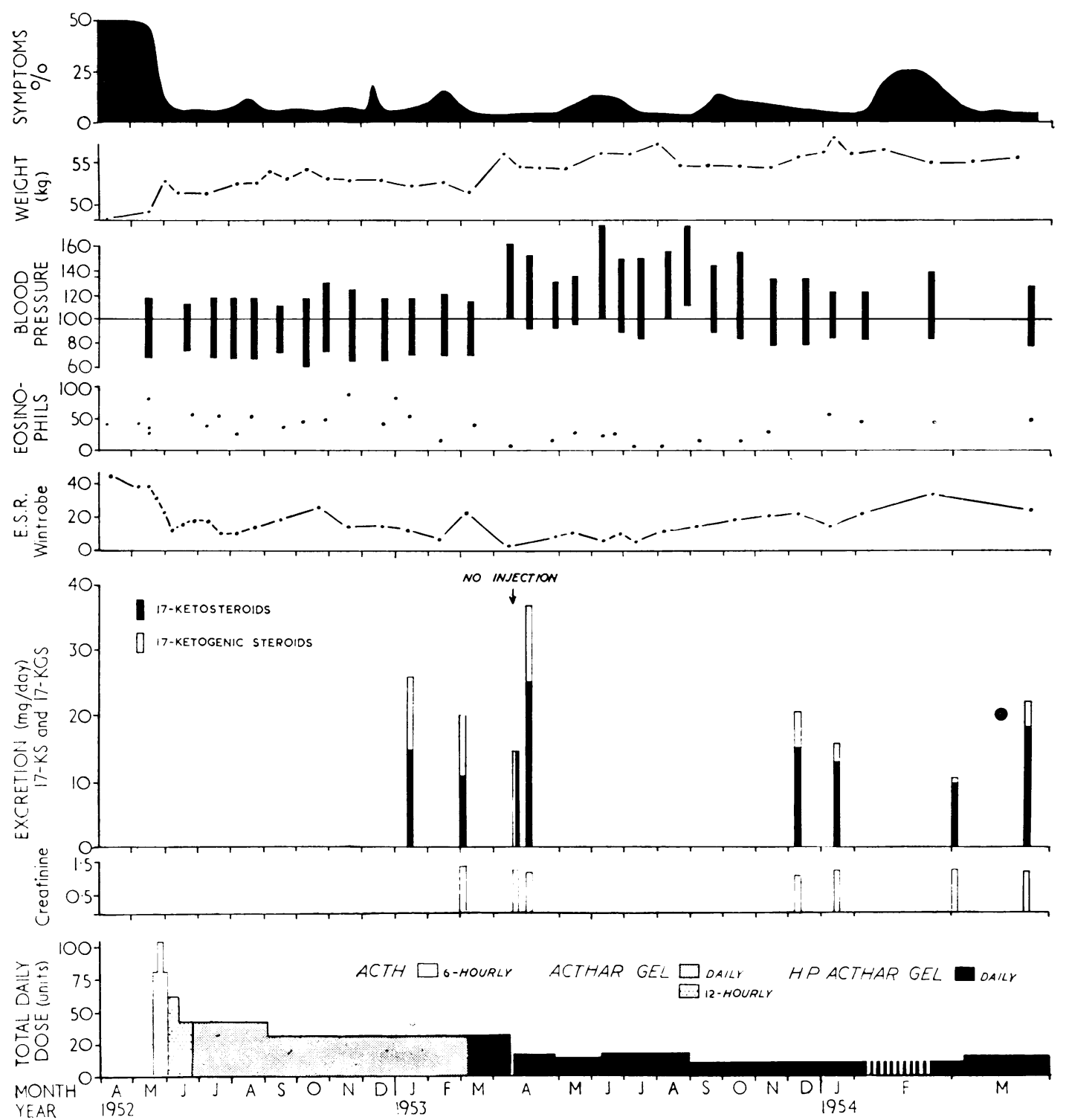

Fig. 6.-Case 4, woman aged 32, ankylosing spondylitis (April, 1952, to March, 1954)

Case 4, a woman aged 32. This patient's disease had run a comparatively mild course for 10 years. The lumbar and dorsal spine was rigid and the chest expansion $\frac{1}{2}^{\prime \prime}$. She came under treatment because of persistent groin pain, and within a few weeks of beginning treatment with ACTH she was able to resume full household duties. There has been no evidence of advance in the disease and her clinical state to-day remains better than before treatment. Minor relapses do not appear to be necessarily followed by further irreparable damage. Fig. 6 shows how a small change in the dosage, when long continued, can markedly affect the blood pressure. This patient had an episode similar to that experienced by Case 3 soon after starting H.P. Acthar Gel. 
Case 5, a man aged 27.- The disease was less advanced in this patient; it had begun 2 years previously and two courses of deep $x$-ray therapy had revealed that the back stiffness and thoracic involvement were largely reversible. ACTH therapy was begun because the back and chest symptoms quickly returned after the second course of $x$-ray therapy, and because of early involvement of the left hip joint. The patient was then unable to work but he soon started again after treatment began and since then has only lost one week from work through his spondylitis. The eosinophil counts show how unreliable such figures may be in the assessment of adrenal stimulation; it is not our practice to make any deductions from them. In the latter months of treatment the adrenal stimulation was little above normal levels.*

That the ACTH was still producing some effect in this patient is made clear by the series of minor relapses that occurred on each day that treatment was missed in January, 1954. It could not be foreseen whether the endogenous supply of ACTH would start up slowly or quickly on cessation of treatment. Fig. 7 (opposite) shows that when the H.P. Acthar Gel was stopped adrenal stimulation was apparently resumed at once, "Butazolidin" (phenylbutazone) $\dagger$ being sufficient to control the symptoms. It must not be assumed from this experience that the endogenous supply of ACTH will return immediately in all cases after prolonged ACTH therapy. Further, the fact that normal amounts of 17-KGS were excreted after treatment was stopped does not necessarily mean that the pituitary. will be able to respond adequately to the stress of major trauma.

Although in this case the disease has shown no evidence of advance during the last $1 \frac{1}{2}$ years, and although the patient's state to-day remains better than before treatment began, one cannot say that it would have been otherwise had he been treated upon more conservative lines. The patient himself claims great benefit and regards the seven hundred or more injections that he has given himself as a small price to have paid for it.

Case 6, a man aged 39, had suffered with pain on the back for 10 years. He was discharged from employment in the mines by a medical board with what was described as a "tuberculous spine". His spine and thorax were rigid and he began treatment because his knees continued to be tightly effused and very painful, in spite of repeated aspirations and the intra-articular injection of hydrocortisone acetate. In the autumn of 1953 the adrenal stimulation was little above normal levels and was clinically ineffective. Unless the adrenal output of hydrocortisone can be measured it is not possible to know whether a relapse is due to an increase in disease activity or to a decrease in the effective dose of ACTH.

To-day the patient's state is little different clinically or radiologically from what it was before treatment was

* Unfortunately there are no pre-treatment assays of 17-KGS for any of these cases as the assay was not in routine use when they began any of these cases as the assay was not in routine use when they began treatment. From the study of many patients since we have found
that the pre-treatment level of excretion lies between 7 and $13 \mathrm{mg}$. that the pre-treatment

$\dagger$ Phenylbutazone in therapeutic doses does not cause adrenal stimulation. begun. It remains to be seen whether a further increase in adrenal stimulation will control the symptoms without $\square$ producing hypertension. The reversed 17-KS/17-KGS ratio of the last assay is not encouraging (Fig. 8, overleaf).

\section{Discussion}

From the study of these six patients can one say $\frac{\overline{\bar{S}}}{\bar{\Phi}}$ that long continued adrenocortical stimulation has $\varrho$ a place in the treatment of ankylosing spondylitis? The patients were selected as those most likely to $\overrightarrow{0}$ run a difficult course, yet in five of the six the disease, $\vec{\overrightarrow{ }}$ as judged by physical signs and $x$-ray appearances, $\vec{\omega}$ has not advanced, and only the first patient (Case 1) is not able to work. In spite of these findings the 으 question can only be answered by a personal opinion, $\vec{\omega}$ since these patients had no controls and the course is of ankylosing spondylitis is so unpredictable. Our $\vec{\circ}$ opinion is that in the really severe cases, who receive

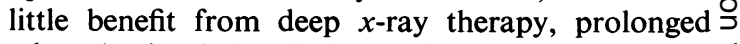
adrenal stimulation is justified, but that it should $\vec{c}$ not be raised to a higher level, nor maintained for a longer period, than is absolutely necessary. For $\overparen{\Phi}$ the less severe cases it should be withheld pending $\overrightarrow{0}$ the results of controlled therapeutic trials. This disease is sufficiently different from rheumatoid $\square$ arthritis to justify a separate therapeutic trial as between adrenal stimulation, hydrocortisone, and deep $x$-ray therapy, plus in each case an agreed schedule of analgesics. Many authorities speak of $\frac{\circ}{\mathbb{D}}$ ACTH therapy as "simply suppressive", but the profound changes seen in the first patient described $\frac{0}{3}$ lead us to question this statement.

Two complications, both due to adrenal stimu- $\frac{}{8}$ lation, were encountered in this study: hypertension and altered adrenal function. A moderate "anti- $\frac{\aleph}{2}$ rheumatic" effect can be maintained without hyper-음 tension, but when a greater effect is needed hyper- 3 . tension supervenes. A simple restriction of salt $\dot{\partial}$ intake did not affect the hypertension. Rigid saltfree diets and the effect of hypotensive drugs were 0 not studied. In Case 2 the hypertension did not appear to be due to an excessive secretion of hydrocortisone. The change in the pattern of $17-\mathrm{KS}$ and 17-KGS excretion, seen in some patients after pro- $\sigma$ longed adrenal stimulation, is a new observation $N$ and must be studied further. Other complications $N$ have been ascribed to ACTH therapy. Some are clearly the direct result of this therapy or of its withdrawal, and many are common to long- $\frac{\mathrm{C}}{\mathrm{D}}$ continued cortisone acetate therapy.* Complications which may or may not be the direct result of this therapy include gastro-intestinal haemorrhage $\overline{0}$

- For an informative discussion see the Symposium published by the Mayo Clinic in November, 1953. 

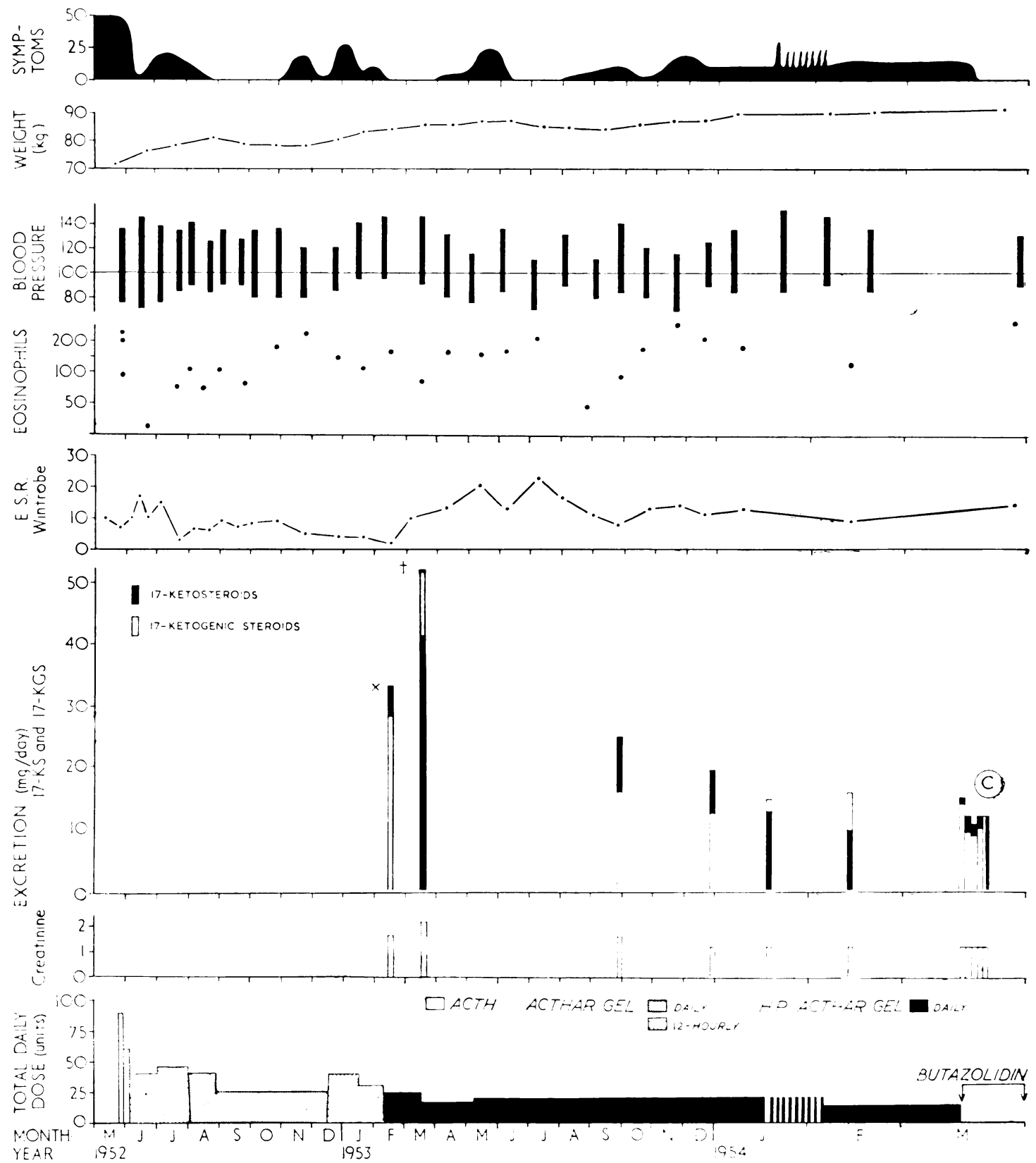

Fig. 7.-Case 5, man aged 27, ankylosing spondylitis (May, 1952, to March, 1954)

* On this occasion sugar was present in the urine. This may have considerably reduced the amount of 17-KGS assayed. Usually a modified technique is used to obviate this interference.

$\dagger$ On the day this 24-hr specimen was collected the patient had a high temperature. It was the first day of a brief illness described by his general practitioner as "influenza". The patient insists that the 24-hr collection was accurate.

(c) A correction was made for creatinine fluctuations in this group of assays. The average creatinine figure was taken. 

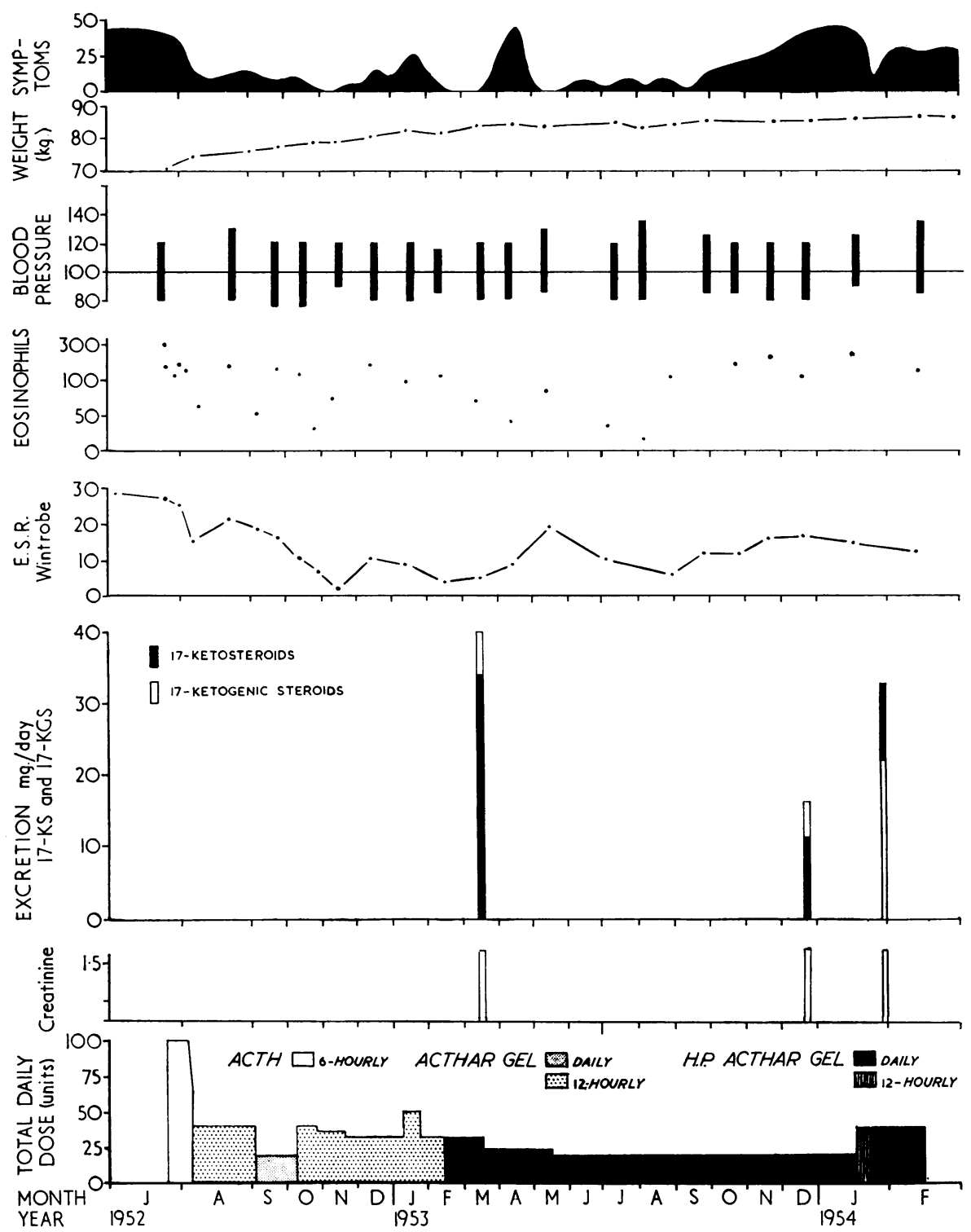

Fig. 8.-Case 6, man aged 39, ankylosing spondylitis (July, 1952, to February, 1954)

and intercurrent infection. Case 2 had an intestinal haemorrhage and Case 1 had two separate virus infections of note during the time of excessive adrenal stimulation: a Bell's palsy with vesicles in the ear, and herpes zoster affecting the 5th nerve, on opposite sides. The other oft-reported side-effects did not trouble these patients.

Figures 3-8 clearly show how impossible it is, even when using highly purified Acthar Gel, to lay down a dose schedule. Unless the 17-KS and 17-KGS excretions are estimated,* it is not possibl हू to assess, except very crudely, the adrenal stimulus?

* Other methods for assaying chemically, in urine, some of the corticosteroid metabolites of hydrocortisone and cortisone hav been described, but they are time-consuming, unsuitable for th average hospital biochemical laboratory, and, it appears to us, les reliable. The same might be said of the assays of "17-hydroxy" steroids" in blood. 
(i.e. the amount of treatment) that is being given. This being so, one wonders whether some of the conclusions drawn from therapeutic trials of ACTH given blindly may not need reconsideration. Our present practice is to assay a $24-\mathrm{hr}$ specimen weekly until a maintenance level has been found, and then to make a monthly test.

\section{Summary}

(1) Six patients suffering from ankylosing spondylitis have been treated with ACTH for from $1 \frac{1}{2}$ to 2 years. Their progress is described.

(2) It is concluded that, as yet, prolonged adrenal stimulation is justified in only the most severe cases.

(3) Problems encountered in the control of ACTH therapy are illustrated and discussed.

(4) Evidence of adrenal dysfunction was seen in at least one patient; this condition is considered as a complication that may attend prolonged adrenal stimulation.

We wish to acknowledge the contributions made by other members of this unit, in particular the work of the sisters and of Mr. George Gibson and Mr. Bob Stubbs who performed the steroid assays. Part of the Acthar Gel used in this work was made available by the Medical Research Council and Nuffield Foundation Joint Committee on Cortisone and ACTH in Chronic Rheumatic Diseases, to whom our thanks are due.

\section{REFERENCES}

Norymberski, J. K., Stubbs, R. D., and West, H. F. (1953). Lancet, 2, 1276.

Sayers, M. A., Sayers, G., and Woodbury, L. A. (1948). Endocrinology, 42, 379.
Simpson, S. A., Tait, J. F., Wettstein, A., Neher, R., Euw, J. van, Schindler, O., and Reichstein, T. (1954). Experientia (Basel), 10, 132 .

Symposium (1953). Proc. Mayo Clin., 28, 641.

West, H. F. (1954). Annals of the Rheumatic Diseases, 13, 56.

\section{Traitement prolongé par l'ACTH de la} spondylarthrite ankylosante

\section{RÉSUMÉ}

(1) Six malades atteints de spondylarthrite ankylosante furent traités pendant un an et demi à deux ans par l'ACTH. On décrit ici leur progrès.

(2) On conclut qu'à l'heure actuelle la stimulation surrénale prolongée n'est justifiée que dans des cas très graves.

(3) On éclaire et discute les problèmes rencontrés au cours du contrôle de la thérapie par l'ACTH.

(4) On a observé chez au moins un malade des signes de dysfonction surrénale; on considère qu'il s'agirait d'une complication de la stimulation surrénale prolongée.

\section{Tratamiento prolongado con ACTH de la espondilitis anquilosante}

\section{SUMARIO}

(1) Seis enfermos con espondilitis anquilosante fueron tratados durante un año y medio a dos años con ACTH. Se describe su progreso.

(2) Se conclude que presentemente la estimulación suprarrenal prolongada se justifica tan sólo en casos gravísimos.

(3) Se aclara y discute los problemas encontrados al controlar la terapia con ACTH.

(4) En un enfermo, al menos, se ha encontrado manifestaciones de disfunción suprarrenal; se las considera como complicaciones posibles de la estimulación suprarrenal prolongada. 